\title{
ERRATUM
}

\section{Summary: FM15 Astronomy for Development - ERRATUM}

\section{Vanessa A. McBride}

doi: 10.1017/S1743921319005349, Published online by Cambridge University Press 03 March, 2020

In the publication of the Astronomy in Focus series, volume XXX, a number of pieces of supplementary material were omitted, including for the above mentioned Focus Meeting 15.

The missing supplementary material has now been uploaded and assigned to this introductory article.

\section{References}

McBride, V. (2018). Summary: FM15 Astronomy for Development. Proceedings of the International Astronomical Union, 14(A30), 551-552. doi: 10.1017/S1743921319005349 